\title{
Localizing Cultural Ethos of Classic Literature: Experiment with an Odia Classic, 'Chatura Binoda'
}

\author{
*1 Rudranarayan Mohapatra \\ *1 P.G. Department of Odia, Utkal University, Vanivihar, Bhubaneswar, Odisha \\ Email: rudranarayanmohapatra830@gmail.com
}

\begin{abstract}
Localization is a process of adopting a culture and/or the reflection of a culture, what is true for Odia literature is more or less true for literature from other states also. Globalization, in many subtle ways, devalues the "local" and encourages a homogenization of culture. Here, localization has a role to play in establishing the uniqueness of the "local," in this instance Odisha or India. Localization assumes vital importance for it establishes a dialogue between language and culture and acquaints communities with other ways of looking at life and experience. Localization is the force that makes it possible to imagine such a map - a map that, when fully sketched, would represent a wonderland of literary riches from diverse languages, all made intelligible to one another. In this paper, to understand the above things along with how the factors of localization components affect cultural ethos, we have adopted the iceberg model of culture and catalyzed it upon an eighteenth-century Odia classic Chatura Binoda, the masterpiece of poet Brajanath Badajena by localizing the same to Hindi language and as a result, determine how the deep-rooted cultural ethos is being loosened irrespective of the knowledge of both language and culture.
\end{abstract}

Keywords: Localization, Cultural ethos, Classical literature, Odia language, Chatura Binoda

\section{INTRODUCTION}

Language mobility is a vulnerable aspect of cultural heritage, and it becomes especially important to preserve it. In the present society, language and literature can be saved not only by collection, communication, compilation, and classification but by computerization. And here the term localization plays a pivotal role for classic language preservation. Crossing cultural gaps is a determining factor of localization. Localization is not only translation but adoption of a text or product to a specific local need. While translation is only one of the several processes of localization, other factors included in the process of localization are the local people's habits, adopting the design and layout of the source text for an effective representation, converting the text as per the local needs, and over the above entire cultural ethos (1). The aim of localization should be that people from a specific locale can use a product without any difficulty in their own language.

Here the source text has been transformed to such an extent that it reflects the target culture need as the expectation, i.e., up to the stage of hyper-personalization. India is a unique country 
with more than 22 officially recognized languages and Odia is the sixth recognized classical status language. Odia language has a valuable literature that needs to be preserved. It is at a high risk of being replaced by foreign languages. And just translation may not serve the purpose. The growth of modern Indian society is slowly destroying its ancient literature, culture, and heritage. In other way, both localization and heritage computing hand-in-hand only can rescue from the crisis and is a present need.

A book recently published by the National Geographic gives a grim prognosis that by the end of the twenty-first century, around 7000 languages will die. This will be a disaster of cataclysmic proportions, because it will mean the death of the cultural perception and knowledge system that is embedded in each language. Therefore, localizing the language texts to another language and culture are a prime need of our time. And whatever steps were being taken, they are not sufficient to overcome the issue. Therefore, the aim of this paper is to adopt the localization process through 'Odia classics preservation framework' and try to figure out the factors that need to be taken care of beyond translation, so a classical age-old product of a language can be adopted be and popularized in a target language culture and community. We have tried here to localize Chatura Binoda ("Clever Humor") of Odia language to its nearby culture and language belt of Hindi and catered to the fact and factor of losing the cultural ethos of a source language in the changing sphere of time and cultural ecosystem.

\subsection{Aims and Objectives}

As per our primary research, Chatura Binoda is a masterpiece of Odia classical language written by an Odia Kabi Brajanath Badajena, a poet of the 18th century. Chatura Binoda, a medieval prose work in Odia unfolds a traditional story-telling style and is written in the then colloquial or local language. The key objectives of this study are:

- to support documentation of classic and heritage literatures;

- to encourage localization of Odia classic and heritage literature for globalization;

- to create a digitized repository of Odia classic literature for cultural and heritage mining; and

- to cater the most factorial aspects of a language that reduces the source language cultural ethos by localizing it to a target language.

\section{REVIEW OF LITERATURE}

The total numbers of manuscripts in India are about five million. Out of these, the manuscripts preserved in Odisha are about 10,000 and they are scattered at different places in Odisha. The above collections have subjects covering almost all sub-branches of Sanskrit and classic Odia literature. With this, many more manuscripts and classical heritage texts are getting published in printed version. But a few of them are translated into other languages.

As per the primary observation, the famous Odia prose text Chatura Binoda was written by Sri Brajanath Badajena during 1755-1765. It is a very interesting compilation of stories based on love and pleasure.

- In 1922, Sri Suryamani Pattanayak edited Chatura Binodafirst time and it was published by 
Cuttack Printing Company. The literate mass of Odisha found serious textual errors in the book.

- After 22 years, in 1944, Pandita Chintamani Acharya critically edited Chatura Binoda and published it.

- A notable Indologist of Odisha, Sri Sudhakar Pattanayak prepared a critical edition based on previously edited versions and a rare palm leaf manuscript found by himself.

- In 1946, under the publication series of Prachi Granthamala, Serial No. 52, it was published by the Students Store, Cuttack, on behalf of the Prachi Samiti.

- Brajanath Granthabali was also edited by Sudhakar Pattanaik and published by Odisha Sahitya Akademi in 1965.

- Again,Chatura Binoda was edited by Debendra Mahanti and published by Friend's Publishers, Cuttack, in 1978. The editor used textual materials from Chatura Binodaedited by Sudhakar Pattanaik.

- On the other hand, Chatura Binoda was translated by Lipipuspa Nayak into English under the title Four Tales for Amusement, which was published by Grassroots, Bhubaneswar, and Indian Writer Series in 2006.

However, the text is not translated into Hindi. Again, it is authenticated and verified that there is no Odia-Hindi lexicon or annotated corpora being developed in Odia,using the contents of medieval Odia literature.Thus, it clearly established that a localization of the end product has actually not happened; it only remains on the bookshelf, making no impact on a target language culture in terms of the role it played in the source language at the time of its creation.

\subsection{Research gap being addressed and the scope}

Whatever the translation work of classical texts happens, happens from other languages like Sanskrit or English into Odia but not vice versa; only a few translations from Odia into English and Sanskrit have happened. Again, any localized texts are only in printed form and not digitized or taken onto a global platform. Thirdly, Odia heritage texts are not yet computerized or used for further heritage computing and/or natural language processing. Localization is a force that makes it possible to imagine a map - a map that, when fully sketched in, would represent a wonderland of literary riches from diverse languages, all made intelligible to one another. Again, heritage computing can highlight the classic Odia texts for a global platform. The present study is thus our pilot project for further research.

\section{METHODOLOGY}

The study has been carried out taking the text of Chatura Binoda, a masterpiece of a classic Odia poet of 18 th century, Brajanath Badajena. The rationale behind selecting the text is that it is written in a story-telling manner expressing the local cultural and spoken language tradition. In the process, we have adopted the iceberg model of localization (3) for a localization of Chatura Binoda for the Hindi-speaking community. We have tried to divide the terminology received from the text into three different groups: (a) Surface Cultural Terminology; (b) Unspoken Expressions from the terminology, (c) Unconscious Expressions from outsiders towards a particular terminology (4). Where the texts' standard meaning is in the first category and the social and cultural ethos expressive terms fall into the second group. But the catering of the third is more difficult and we take the help of Hindi people, less aware of the 18th- 
century Odia literary ecospheres and try to create a relationship chain of terminology for a better localization. In this, the concept of write/wrong, match/mismatch, emotional response, etc. are taken care of to complete the experiment as a whole and to get the desired output.

\section{BENEFITS}

Odisha is a multilingual state and in this scenario this project would prove to be beneficiary in information gathering and knowledge acquisition. This will lead to inter-regional interaction and communication, helping knowledge and resource accession and generation, and above all globalization of Odia heritage and cultural texts. The ultimate goal of the system is to preserve our cultural heritage and explore the cultural ethos that could help us to understand the preparation of a universal-culture model for extracting cultural ethos from a localized terminology. This environment will create a scope to represent heritage knowledge data for further research to the mass and primary linguistics data could be used for language processing to find out knowledge input in other manuscripts.

\section{LOCALIZATION AND FACTORS OF LOSING CULTURAL ETHOS}

Culture is a combination of different elements such as values, morals, beliefs, rules, rituals, traditions, indigenous knowledge, and customs; and these are passed from generation to generation within the community or in a particular locality. As a process of localization, the invisible traits within a text carry higher importance than the visible elements like dressing, food habits, tools and technique, etc. While experimenting with Chatura Binoda, we came across different features of a text that affect the cultural ethos of a community or a locality. It may be language, content, singing style, choice of words and senses, knowledge representation, etc. Out of these, some points can be explored here for a better understanding.

\subsection{Chatura Binoda Content}

Chatura Binoda is the only prose work of Brajnath Badjena but the art form of story is clearly expressed in it. Following the narrative style of Sanskrit—such as seen in Hitopadesh, Panchatantra, or Kadambari - Chatura Binoda has a number of sub-stories and branch-stories which are narrated separately and connected with the rootstory. There is a beautiful story-tree (Figure 1) with one root story, four sub-stories, and eighteen branch stories. The original story begins with a meeting between Chanchalakshi and Mohanaanga and on the night of the reunion, Sakhi's request is to tell a story for the glorious celebration of Gauribrata observed by Chanchalakshi. The progress of story runs through various episodes, namely Haasa Binoda (fun of laughing), Rasa Binoda (fun of enjoyment), Niti Binoda (fun of justice), and Priti Binoda (fun of love). The sub-stories are interwoven with the main stories. The great story tree of this work has one branch story in Haasa Binoda, three branch stories in Rasa Binoda, three branch stories in Niti Binoda, and nine branch stories in Priti Binoda. 


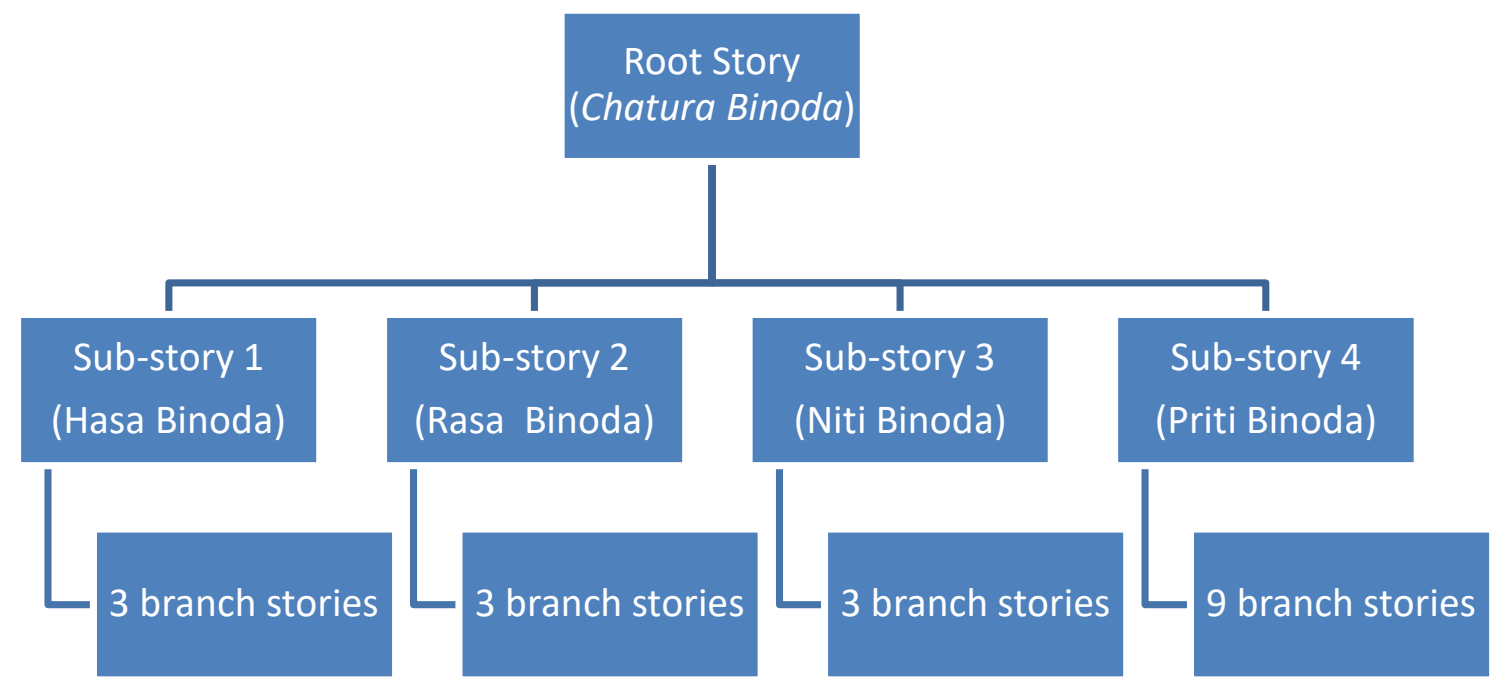

Figure 1: Tree map of Chatura Binoda

\subsection{Language and Narration}

The language of Chatura Binoda is the language the people of the time spoke. Thus, Badajena goes on to start the story, saying, "Hey folks, let me hear you say something in the native language called Chatura Binoda." However, its content also includes a combination of Sanskrit verses, parodies, and sentences. So, even though its language is a native language, we can divide it into three parts: Sanskrit, Sanskritized Odia, and Odia. Again, it is a combination of both verse and prose. According to Karunakar Kar, it is a prose poem. However, this poetry has long followed the rhetorical principles.

Looking closely at the phraseology of the text, many18thcentury local Odia terminology, whose present forms are already modified in standard Odia form, are clearly seen. Therefore, as compared to the reading of the original text, the reader of a localized book may not be able to capture the entire cultural or linguistic flavor and discourse. Some of these terms and their present vocal form are presented below as a ready reference (Table 2).

Table 1: Chatura Binoda terminology

\begin{tabular}{|c|c|c|}
\hline Term in Chatura Binoda & English Meaning & Modern Term \\
\hline Eka Kathaae & A story & Gotie kathaa \\
\hline Shunimaa heu & Listen up & Shunibaa heu \\
\hline Boli kahi & It is said & Kuhaajaae \\
\hline Eka baishya kanyaa & A merchant girl & Jane baishya \\
\hline Eka dinakare & In a day & Dine \\
\hline Aapana bije kara & You please come & Aapana aasantu \\
\hline paaLati & Foster wife & PaaLitaa Stri \\
\hline
\end{tabular}




\subsection{Named entity and its semantic relationship}

Although the subject of Chatura Binodais kings and queens, it gradually expands to the common life. Therefore, the characters from every sphere of society such as raajaapua(prince), raajaajhia(princess), mantri(ministers), saadhab(saint), katuaala(the gatekeeper cum messenger for the king), dwaari(gatekeeper), vaishyakanyaa(merchant girl), jyotisha(astrologer), vaidya(physician), brahmin(priest), naapit(barber), ganikaa(prostitute), Shabar(name/person of a tribe), natuaa(dancer), gopaal(milkman), maadaliaa(drum-beater), raajguru(king's teacher), poili(maid), keluni(conch seller), etc. come in a variety of contexts of the story and provide an extensive range of experience."The proper names are chosen carefully to reflect the character, status, fate and future of characters either realistically or satirically" (5). While the naming of characters is similar in some respects to their qualities or temperament, at times their names carry the exact opposite of the qualities they possess. And this is a big challenge for localization. The semantic aspects of some names can be analyzed here (Table 2).

Table 2: Names in Chatura Binoda and IM \& Ref-M relationship

\begin{tabular}{|c|c|c|c|}
\hline Names & $\begin{array}{l}\text { Implied Meaning } \\
\text { (IM) }\end{array}$ & Reflected Meaning (Ref-M) & $\begin{array}{c}\text { Relationship of IM } \\
\text { \& Ref-M }\end{array}$ \\
\hline Chancalakshi & $\begin{array}{l}\text { Woman with fast- } \\
\text { moving eyes }\end{array}$ & $\begin{array}{l}\text { The character has slow motion, } \\
\text { soft teeth, smiling face, quick- } \\
\text { witted, gentle voice with gentle } \\
\text { but moderate }\end{array}$ & Just opposite \\
\hline Mohanaanga & Fascinating body & $\begin{array}{l}\text { He concentrate on all things, } \\
\text { despite all the possibilities of } \\
\text { losing his character }\end{array}$ & Just opposite \\
\hline Surekhaa Nadi & $\begin{array}{l}\text { The main character } \\
\text { of a river is that it } \\
\text { flows in a curved } \\
\text { line }\end{array}$ & 'Surekha' meansa straight line. & Just opposite \\
\hline $\begin{array}{l}\text { Naagaabharana } \\
\text { Mahesh }\end{array}$ & $\begin{array}{l}\text { Lord Shiva } \\
\text { surrounded by } \\
\text { snakes }\end{array}$ & Lord Shiva surrounded by snakes & Appropriate \\
\hline Angadhara Raja & Cheer organ king & $\begin{array}{l}\text { The people of hiscountry are } \\
\text { begging from other countries } \\
\text { andtheking survives through } \\
\text { their prayers }\end{array}$ & Just opposite \\
\hline $\begin{array}{l}\text { Karmaandha } \\
\text { Purohita }\end{array}$ & $\begin{array}{l}\text { Priest should be } \\
\text { aware of } \\
\text { karmakaanda }\end{array}$ & Karmakanda-ignorant priest & Just opposite \\
\hline BiLapamukhi & $\begin{array}{l}\text { Woman with a } \\
\text { mourning face }\end{array}$ & $\begin{array}{l}\text { The act of making a mourner to } \\
\text { laugh is the exact opposite }\end{array}$ & Just opposite \\
\hline
\end{tabular}




\begin{tabular}{|c|c|c|c|}
\hline & & activity & \\
\hline $\begin{array}{l}\text { Marjaaramukha } \\
\text { Rajakumar }\end{array}$ & $\begin{array}{l}\text { A prince must be } \\
\text { beautiful and } \\
\text { virtuous }\end{array}$ & $\begin{array}{c}\text { Born of a mouse hole and its face } \\
\text { is like a cat's }\end{array}$ & Just opposite \\
\hline $\begin{array}{l}\text { Ratnasekhar } \\
\text { Bania }\end{array}$ & $\begin{array}{l}\text { The merchant } \\
\text { holding the gem }\end{array}$ & $\begin{array}{c}\text { He went to trade on the island of } \\
\text { Mandar }\end{array}$ & Appropriate \\
\hline Narmada & $\begin{array}{l}\text { Name of a river, so it } \\
\text { can go wherever it } \\
\text { finds a way to flow }\end{array}$ & $\begin{array}{c}\text { Going beyond its banks is one of } \\
\text { the features of a river. Here } \\
\text { Narmada, the wife of } \\
\text { Ratnasekhar meets with } \\
\text { Kishorchandra in the absence of } \\
\text { her husband. }\end{array}$ & Appropriate \\
\hline Chandraloka Raja & $\begin{array}{l}\text { A king with cool } \\
\text { qualities like the } \\
\text { moonlight }\end{array}$ & $\begin{array}{c}\text { The king's religious policy in the } \\
\text { kingdom of Kirtimandan is } \\
\text { unique in its qualities, judgment, } \\
\text { heroism, nobility, and so on. }\end{array}$ & Appropriate \\
\hline $\begin{array}{c}\text { ChitrakanThikaa } \\
\text { Shari }\end{array}$ & \begin{tabular}{|c|} 
Shari (a female \\
parrot) whose voice \\
is depicted as an \\
artwork
\end{tabular} & $\begin{array}{l}\text { Shari who is given human } \\
\text { qualities and is one of the } \\
\text { witnesses to the marriageof } \\
\text { Kundarekha with the Brahmin }\end{array}$ & Appropriate \\
\hline $\begin{array}{l}\text { Dhyaananda } \\
\text { Gosain }\end{array}$ & $\begin{array}{l}\text { Becomes happy in } \\
\text { meditation }\end{array}$ & $\begin{array}{l}\text { He is proficient in all scriptures } \\
\text { and knows everything about } \\
\text { meditation }\end{array}$ & Appropriate \\
\hline
\end{tabular}

Chatura Binoda is a treasure of characters. In our counting, almost sixty character, both animate and inanimate, appear in the context of storytelling and build the story as desired.

\subsection{Phrasal Entity in and its Localized Discourse}

In Chatura Binoda, the writer used many terms to express laughter, satire, or deception and those terms with reference to the textual context imply just its opposite of their surface meaning or etymological meaning. So, in the process of localization, these terms lose their contextual meaning and the localized discourses suffer by deficient cultural ethos.

Table 3: Phrasal entity and its localized discourse

\begin{tabular}{|c|c|c|c|}
\hline Phrasal Entity & Meaning & Discourse & English Meaning \\
\hline Punyaprataapa Sakaashanru & $\begin{array}{c}\text { Because of the } \\
\text { power of virtue }\end{array}$ & Paapara Prabalyaru & $\begin{array}{c}\text { From the power of } \\
\text { sin }\end{array}$ \\
\hline Se Pruthi & That earth & KelibaTa Nagara & Kelibata kingdom \\
\hline Dharmabharana Mantribara & $\begin{array}{c}\text { Minister of } \\
\text { justice }\end{array}$ & Adharmi Mantri & $\begin{array}{c}\text { Minister of } \\
\text { injustice }\end{array}$ \\
\hline Bhaalapatta Uchha & High Forehead & $\begin{array}{c}\text { UchaKapaaLi (in a bad } \\
\text { sense) }\end{array}$ & Bad luck \\
\hline Chaturtha Kaala & Fourth stage & Baardhyaka & Old age \\
\hline Paanilaagi hebaa & To be watered & Saucha Hebaa & To be washed \\
\hline
\end{tabular}




\begin{tabular}{|c|c|c|c|}
\hline maDasaDha chumbana & $\begin{array}{c}\text { Deceased body } \\
\text { kissing }\end{array}$ & Bilaapamukhira chumbana & $\begin{array}{c}\text { Kissing of } \\
\text { Bilapanukhi (the } \\
\text { crying face girl) }\end{array}$ \\
\hline Uansha nishira chumbana & $\begin{array}{c}\text { The moon of the } \\
\text { new moon'snight }\end{array}$ & $\begin{array}{c}\text { Amabasyare chandra or } \\
\text { asambhaba }\end{array}$ & Impossible \\
\hline $\begin{array}{c}\text { ChuDaaDhinki } \\
\text { PaDilaakhyani }\end{array}$ & $\begin{array}{c}\text { As soon as the } \\
\text { wooden tipped } \\
\text { pestle collapsed }\end{array}$ & Raat paahibaa Purbaru & Before nightfall \\
\hline
\end{tabular}

\subsection{Localization of Poetic Construction and Parody}

A careful look at the language reveals that it is replete with stylistic devices as well amazingly varied in scope and range. The writer often adopts poetic statements with superlatives, hyperbolic, adornments, and metaphors (6). In addition, the use of musical expressions throughout the text also creates cultural sentiments for the reader. While localizing it to another language, the value of cultural sentiment and ethos diminish in proportion. For instance, Marjaramukhi sings a parody in the king's court that expresses the cultural ethos and demonstrates prevalence of the caste system.

So,Chatura Binoda represents the literary strength of spontaneity with participatory humor of the masses, but at present the source Odia language has lost almost all cultural words prevalent centuries back because of the dominating colonial languages.

\section{THE OUTCOMES FROM THIS STUDY}

For the choice between the original and localized version of a classical text, the original one dominates the localized one. However, the localized versions our classic epics such as Mahabharata or Ramayana, and Bhagavatam, even if originally written in Sanskrit, are also equally popular in various local ecospheres.

Despite translation or localization of the original text in other languages, it does not attract the readers from those localized spheres. There are many typical and cultural words which are exclusively attached to a culture of one locale. For someone not belonging to that culture, an exact localization of the term will not happen. For instance, the term poili may be translated as "maid," but in the cultural context of Odisha, 'poili' the maid who comes with a bride as a part of her dowry, stays with her for life, and who is generally a young widow or someone who has no other means of sustenance.

In same there are other cultural terms in the text such as 'Maaluni', 'Champi' etc. Where, the term 'Maaluni' is a lady has a number of characters such as she is very clever, she can be a made; she can take decision at the time of a crisis to save her party; she can also be a diplomat and with many other knowledge and characters. Another word is 'Champi' means a special lady whose character is very outspoken and thinks own self as a clever, but practically she is very foolish in others eye. 
Therefore, the cultural ethos and number of cultural gaps makes it difficult for the reader to understand the localized text as the semantic and pragmatic discourse of originality lost in the localized text. Irrespective of this, we have tried to find out the gap factors that particularly annoy the target readers and negatively impact their enjoyment of the localized material. As was observed earlier, most of the target readers below age of eighteen years although notice the mistakes continue reading the localized version of the text. What puts them off is the inaccurate translation and inability to understand some local Odia terminology. They, however, develop a cognizance of the text as their understanding increases.

On the other hand, readers above eighteen are less tolerant to an inappropriate style and to inappropriate transference of the source language terms to the target language, even if some terms are presently not in the target language and culture or have faded away. As the text has a number of Sanskrit words derived from a combination of more than one vocabulary and is able to express a pictorial discourse, this also creates trouble for the localizer to transfer the knowledge as it is. Again, the musicality and its rhythmic value also show another gap for both the localizer and the target readers to capture cultural ethos of the source text.

\section{CONCLUSION}

Quality assurance of localization is not only confined to linguistic testing and translation but is also much related to the quality review and adopting process of cultural factors. Again, as the culture is dynamic, to capture the entire cultural ethos is always difficult for any localizer when localizing a century-old classic text. Localization is an adaptation to a culture where the language is the core. With this, the biggest challenge is to connect the theoretical statements to the real process of extracting cultural ethos terminology. Irrespective of this, the level of a localized target text to be user oriented can be developed with a proper social and usability survey and by adopting a preparation and linking of cultural ethos an absorption-oriented terminology.

\section{REFERENCE}

[1]. Yulia Molostova. "What Makes Localization Good? Russian vs. Chinese Gamers", GALA. (2017):

[2]. https://www.gala-global.org/publications/what-makes-localization-good-russian-vs-chinesegamers

[3]. Peter Sandrini (Innsbruck). "Localization and Translation", In: MuTra Journal. 2 (2008): LSP Translation Scenarios, Selected Contributions to the EU Marie Curie Conference Vienna 2007. Edited by Heidrun Gerzymisch-Arbogast, Gerhard Budin, Gertrud Hofer. Saarbrücken: ATRC 167-191. http://www.petersandrini.net/publik/localiz.pdf

[4]. The Iceberg Model Explained' Haygroup, (2015):

[5]. https://www.londonleadershipacademy.nhs.uk/sites/default/files/uploaded/Introduction\%20to \%20the\%20Iceberg\%20model_FINAL_25\%2003\%202015.pdf

[6]. Kenzie Shofner. "The Iceberg Model, Localization and Cultural Context." Ulg's Language Solutions Blog, February 24, 20

[7]. https://www.unitedlanguagegroup.com/blog/translation/iceberg-model-localization-cultural- 
context.

[8]. Lipipushpa Nayak. "Brajanath Badajena's "Chatura Binoda" An Introduction," Indian Literature 45, 6 (206(2001)): 35-46.

[9]. Lipipushpa Nayak. "Brajanath Badajena's "Chatura Binoda" An Introduction," Indian Literature 45,6 (206(2001)).

[10]. Jenny Börjel, "Language-Specific Quality Issues In A Real World Localization Process", Master Thesis In Cognitive Science, Linkopings Universitet, (2007).

[11]. Bert Esselink, Arjen-Sjoerd de Vries and Shiera O'Brien. "Practical Guide to Localization", Publisher John Benjamins Publishing Company

[12]. https://search.proquest.com/docview/2132100679/6FE38582BC4140FEPQ/11? accountid=17 5701

[13]. Dimitra Anastasiou, Reinhard Schäler. "Translating Vital Information: Localization, Internationalization, and Globalization", Centre for Next Generation Localisation, Localisation Research Centre, Department of Computer Science and Information Systems, Limerick, Ireland; http://www.danastasiou.com/Publications/Syntheses.pdf

[14]. 'Chatura Binoda re thibaa Charitramaanankara Bibarani' Saturday July (2019: http://kantiokatha.blogspot.com/

[15]. Kabibara Brajanatha Badajena, 'Chatura Binoda', Brajanath Granthabali,Vol 1, Edited by: Shri Sudhakar Pattanayak

[16]. Dr. Smita Mohanty, "Chatura Binoda Sancracha O Alochana", Friends Publishers, Binod Bihari, ISBN: 81-7401-173-0, 1996

[17]. Dr. Devendra Mohanty (Editor), 'Chatura Binoda', Friends Publishers, Binod Bihari, ISBN: 81-7401-457-6, Tenth Edition 